Article

\title{
Screening Carpet Substrate Interferences in Arson Identification by Solid Phase Microextraction and Gas Chromatography-Mass Spectrometry
}

\author{
Alyssa Aldrich, Edna Gennarino-Lopez, Gabriel Odugbesi, Kaylandra Woodside and \\ Shokouh Haddadi * (D) \\ Department of Chemistry, State University of New York at Oswego, Oswego, NY 13126, USA; \\ aaldrich@oswego.edu (A.A.); egennari@oswego.edu (E.G.-L.); godugbes@oswego.edu (G.O.); \\ kwoodsid@oswego.edu (K.W.) \\ * Correspondence: shokouh.haddadi@oswego.edu
}

Received: 23 October 2020; Accepted: 16 November 2020; Published: 19 November 2020

\begin{abstract}
The sample analysis and data interpretation is the most challenging step of fire debris analysis, due to the presence of combustion and pyrolysis products in the substrate material. In this study, a headspace solid phase microextraction (HS-SPME) procedure was applied to the extraction of combustion and pyrolysis products from three commonly used carpet substrate materials, made of nylon 6,6 and polyesters. Each carpet sample was burned with and without two different ignitable liquids (ILs), i.e., gasoline and kerosene, and the Total Ion Chromatograms (TICs) and extracted ion profiles of characteristic class compounds of ILs were obtained and compared to those of unburned neat ILs, using gas-chromatography mass spectrometry (GC-MS), to study the possible interferences of these substrate materials in fire debris analysis.
\end{abstract}

Keywords: solid-phase microextraction (SPME); gas chromatography-mass spectrometry (GC-MS); extracted ion profile; fire debris; carpet substrate; arson

\section{Introduction}

Arson is defined as a willful and malicious burning of property [1] and is considered a crime. According to the National Fire Protection Association (NFPA), approximately 1.3 million fires were responded to in the year 2019 in the United States [2], of those, 33,395 were reported as arson by the FBI [3]. Fire investigators follow standard scientific approaches to determine the origin and cause of fire [1]. The determination of the cause of fire is defined as the identification of a fuel, ignition source and the oxidizer [4]. If the use of ignitable liquids is suspected, fire debris is collected and sent to the laboratory to be analyzed for the presence of ignitable liquid residues (ILRs) [4].

Ignitable liquids are classified into two major categories: petroleum-based and non-petroleum based [5]. Petroleum-based ignitable liquids are derived from crude oil and are more often encountered in structure and vehicle fires [4,5]. The American Society of Testing and Materials (ASTM) has further classified petroleum-based ignitable liquids according to their boiling point range (light, medium, and heavy) and general chemical composition [4,5]. The petroleum-based ignitable liquids commonly encountered in ILR analysis are gasoline and kerosene [5]. Gasoline is mainly composed of aromatic compounds (from 4-carbon long chain, C4, to 12-carbon long chain, C12), and contains small amounts of alkanes [4]. Kerosene is classified as a heavy petroleum distillate in ASTM E1618 and contains both aliphatic and aromatic compounds in the C8-C20+ range [4].

Since ILRs mainly contain a complex mixture of volatile compounds, extraction followed by gas chromatography coupled to mass spectrometry (GC-MS) is the most predominant and effective 
technique for their analysis in fire debris [6]. The current standard extraction methods used for the pre-treatment of fire debris samples are: headspace concentration $[7,8]$, and solvent extraction $[5,9]$. Among these methods, passive headspace concentration with activated charcoal (ASTM E1412-12) [7] is the most widely used confirmatory test in the United States [5]. In this method, an activated charcoal strip (ACS) is suspended in the headspace of the fire debris in a sealed container and the container is heated at the recommended temperature for relatively long durations to allow the desorption of ILRs from the fire debris into the headspace so that they can be adsorbed on the activated charcoal strip adsorbent. The activated charcoal strip is then removed from the headspace and the adsorbed compounds are desorbed into an organic solvent which is directly analyzed by GC-MS using liquid injection [5,7]. Although simple and inexpensive, the activated charcoal strip method is time-consuming and requires the use of toxic organic solvents such as carbon disulfide [6]. Another passive headspace extraction method that has become popular in recent years due to being fast and solvent-free is solid phase microextraction (SPME) [8]. In this technique, the sorbent is a polymer, coated on a fiber, which is mounted on a syringe-like device. The sorbent is exposed to the headspace of the heated fire debris in a sealed container for a relatively short extraction time, e.g., $30 \mathrm{~min}$. The sorbent is then removed from the headspace and directly injected into the injection port of the GC-MS for thermal desorption and analysis [4,5]. Although SPME is considered a screening test, it can provide fast and diagnostic information to forensic scientists [5]. Compared with the activated charcoal strip method, solid phase microextraction is not an exhaustive method and the fire debris sample analyzed using SPME can be tested again if required [8]. Furthermore, small, commonly used glass vials (e.g., $10 \mathrm{~mL}$ screw cap vials) can be used for SPME, which can be conveniently heated in the autosampler heater at a controlled temperature. Unlike activated charcoal strips, SPME fibers can be baked prior to extraction to avoid any contamination and are re-used for several extractions.

The sample analysis and data interpretation are perhaps the most challenging steps of fire debris analysis. The identification and classification of ILRs is performed by a pattern recognition technique, which is a visual comparison of the Total Ion Chromatograms (TICs) obtained from the fire debris sample to those of reference ignitable liquids (RILs) obtained under the same chromatographic conditions [5]. However, the chromatograms obtained from an extracted sample from the headspace of fire debris not only include the ignitable liquid residues, but they also represent volatile compounds present in the matrix - substrate background products-as well as pyrolysis and combustion products, which can complicate the data interpretation, especially when the ILRs concentrations are very low. Thus, the standard test method for the interpretation of ILRs extracted from fire debris samples, ASTM E1618-14 [10], recommends that each laboratory should have both their own reference ignitable liquid (RIL) database, as well as a database of commonly used substrate materials that do not contain ILs [6]. However, since not all laboratories can collect and keep such a large collection of reference substrate samples, the National Center for Forensic science (NCFS) maintains a database known as the Ignitable Liquid Reference Collection (ILRC) [6,11]. Moreover, gas chromatography coupled to mass spectrometry provides extracted ion monitoring, which is a more accurate technique for the identification and classification of ILRs. In this technique, fragment ion(s) related to different class compounds known to be present in each class of ILs are extracted from the total ion chromatograms of the heated extracted fire debris and the obtained chromatogram, which is known as extracted ion profile, is visually compared to the extracted ion profile of that class of compounds in neat ignitable liquids. For example, to decide if gasoline is present in a fire debris sample, fragment ions representative of at least alkanes, aromatics and oxygenates must be reviewed besides the total ion chromatogram [12]. This technique is particularly helpful when volatile organic compounds caused by substrate background products and pyrolysis and combustion products are present at higher concentrations compared to the ILRs and can skew the total ion chromatogram [12]. Although the ILRC database is a comprehensive library of chromatograms obtained from commonly used ILs and substrates and is gathered according to the ASTM guidelines [6], the data is obtained using the activated charcoal strip method and to our knowledge, there is no database available for laboratories that use the SPME method, which can 
produce a different chromatographic pattern for substrate materials due to the difference in physical and chemical characteristics of the sorbent, sorbent capacity, extraction temperature and extraction time. Besides being solvent-free, fast, reusable, and non-exhaustive, another advantage of SPME over the ACS method is the smaller sample size required for the substrate material analysis. For example, while the ACS method required burning a $6 \mathrm{~cm}^{2}$ sample of the substrate carpet material [11], the SPME method requires a small sample size (e.g., a single fiber) for analysis. Therefore, SPME can provide significant substrate information even in cases where the sample size limits the use of the ACS method. Moreover, the ILRC database does not provide the chromatograms obtained from substrates burned in the presence of different ignitable liquids. Since the pyrolysis products can be different at the presence of different ILs, due to the change in combustion temperature, investigating the chromatograms of carpets in the presence of a particular IL is useful in arson identification.

Due to the advantages of SPME, forensic scientists have shown more interest in using SPME for the analysis of accelerants in fire debris $[13,14]$. Fetig et al. evaluated an SPME method for the analysis of ILs in fire debris [13] and Li Ying et al. were able to demonstrate that the chromatograms obtained from burning a brand of carpet differed in the presence or absence of gasoline and that some of the gasoline target compounds are also found in the pyrolysis products of carpet [14]. However, the extracted ion profiles have not been investigated. The main objective of the current study is to apply the proposed SPME method by Fetig et al. to obtain the total ion chromatograms as well as the extracted ion profiles of three different carpet substrates at different conditions, namely, burned without ILs and burned at the presence of two commonly used ILs, i.e., gasoline and kerosene. Considering the advantages of SPME over other extraction techniques and the recent interest in using this method in forensic laboratories, the provided data are valuable in demonstrating the reliability and robustness of the SPME as an alternative technique to ACS in fire debris analysis.

\section{Materials and Methods}

\subsection{Materials and Reagents}

Methanol and ethyl acetate were purchased from Fischer Scientific (Pittsburgh, PA, USA). Kerosene was obtained from Lowe's Home Improvement Store (Mooresville, NC, USA), and gasoline was obtained from a local gas station. Three different carpet samples were obtained from Lowes: Stain Master Pet Protect (Nylon 6,6), Stain Master Essential Carpet (polyester), and Berber 100\% Dyed Polyester (polyester). DVB/CAR/PDMS SPME fibers and manual holders were purchased from Fischer Scientific.

\subsection{Sample Preparation}

For preparing the samples, a diluted stock solution of ILs was first prepared. A $1.00 \mathrm{~mL}$ portion of a 9:1 ratio mixture of methanol and ethyl acetate was spiked with $10 \mu \mathrm{L}$ of the Ignitable Liquid (IL), either gasoline or kerosene, vortexed for $1 \mathrm{~min}$ and refrigerated.

To obtain the IL sample for SPME extraction, $10 \mu \mathrm{L}$ of the diluted IL stock solution was transferred into a $10 \mathrm{~mL}$ septum screw cap vial together with $2 \mathrm{~mL}$ of deionized (DI) water. To prepare the burned carpet samples, approximately $0.1 \mathrm{~g}$ of carpet was placed on a watch glass and ignited using a lighter and burned until charred (for a duration of $30 \mathrm{~s}$ ) in the open air. To prepare the carpet burned in the presence of the ILs, approximately $0.1 \mathrm{~g}$ of carpet was spiked with $10 \mu \mathrm{L}$ of diluted IL stock solution, set for $1 \mathrm{~min}$, and burned on a watch glass until charred and placed in a vial together with $2 \mathrm{~mL}$ of DI water.

\subsection{Head Space Solid Phase Microextraction}

The HS-SPME method evaluated by Fetig et al. [13] was used for the head-space analysis of all samples. Each sample was first incubated at $30{ }^{\circ} \mathrm{C}$ for five minutes and the preconditioned $\mathrm{DVB} / \mathrm{CAR} / \mathrm{PDMS}$ fiber was inserted into the cap septum and exposed to the head-space of the sample 
for $30 \mathrm{~min}$. The fiber was then removed and injected into the gas chromatogram injector at $250{ }^{\circ} \mathrm{C}$ for the desorption time of two min.

\subsection{Instrumentation}

A Thermo Scientific Trace 1310 gas chromatograph (Thermo Fisher Scientific, Waltham, MA, USA) interfaced with a ISQ Single Quadrupole mass spectrometer (Thermo Fisher Scientific, Waltham, MA, USA) with the XCalibur software program equipped with NIST library was used to perform the GC-MS analysis. The GC was equipped with a TG-SQC Thermo Fischer Scientific capillary column $(30 \mathrm{~m} \times 0.25 \mathrm{~mm} \times 0.25 \mu \mathrm{m})$. The injection temperature was $250{ }^{\circ} \mathrm{C}$ and the injector was used in the splitless mode for $0.3 \mathrm{~min}$ starting with the SPME injection, followed by split mode with a split flow of $100 \mathrm{~mL} / \mathrm{min}$. The helium carrier gas flow rate was $1.7 \mathrm{~mL} / \mathrm{min}$. The GC oven temperature was initially held at $40{ }^{\circ} \mathrm{C}$ for $3 \mathrm{~min}$ and increased to $160^{\circ} \mathrm{C}$ at a rate of $5{ }^{\circ} \mathrm{C} / \mathrm{min}$ and then increased to $280^{\circ} \mathrm{C}$ at a rate of $60^{\circ} \mathrm{C} / \mathrm{min}$ and held for $1 \mathrm{~min}$. The transfer line temperature was set at $310^{\circ} \mathrm{C}$, the electron ionization source was operated at $70 \mathrm{eV}$ and the quadrupole mass analyzer was operated at full scan mode $(m / z=50-500)$.

\subsection{Data Analysis}

The total ion chromatograms and the extracted ion profiles were obtained for each sample using the XCalibur software. The selected fragment ions for each class compounds were as follows: $\mathrm{m} / \mathrm{z}=57.0$, 71.0, 85.0, and 99.0, for extracted alkane profile; $m / z=55.0,69.0,83.0,97.0$ for extracted cycloalkanes and alkenes profile; $m / z=91.0,105.0,119.0$, and 133.0, for extracted aromatics (alkylbenzenes) profile; $m / z=128.0,142.0,156.0$, for extracted polynuclear aromatics; and $m / z=117.0,118.0,131.0,132.0$, 145.0, 159.0 for extracted indane profile [15]. The target compounds and pyrolysis products were identified by a comparison of the fragmentation pattern of the mass spectrum of the unknown with the reference mass spectra in the NIST library. The mass spectrum matching score is reported as Reverse Match Factor (RSI).

\section{Results}

\subsection{Extracted Ion Data for Unburned Neat Ignitable Liquids}

The total ion chromatogram obtained for unburned neat gasoline sample (Figure 1a) was consistent with what was reported in the literature for neat gasoline analyzed using HS-SPME in terms of the retention time and abundance of the volatile organic compounds [13,14].

The extracted ion profiles could not be found in the literature for the SPME technique; however, the extracted profiles (Figure $1 \mathrm{~b}-\mathrm{f}$ ) were visually comparable with those provided in the literature using the activated charcoal strip (ACS) method [11]. It should be noted that the extracted profiles obtained by the SPME method can be different in terms of abundance of the peaks with those obtained using activated charcoal strip due to the differences in both the physical properties and the capacity of the extraction phases used in the two methods [5]. Nevertheless, the extracted profiles of gasoline were clearly distinguishable and characteristic of neat gasoline. The gasoline target compounds were also identified in the chromatograms: toluene $(\mathrm{RT}=3.28 \mathrm{~min}, \mathrm{RSI}=929), m$ - and $p$-xylene $(\mathrm{RT}=5.85$ $\mathrm{min}, \mathrm{RSI}=924), o$-xylene $(\mathrm{RT}=6.51 \mathrm{~min}, \mathrm{RSI}=931)$, trimethylbenzene $(\mathrm{RT}=10.54 \mathrm{~min}, \mathrm{RSI}=904)$, and indane $(\mathrm{RT}=10.92 \mathrm{~min}, \mathrm{RSI}=921)$. 

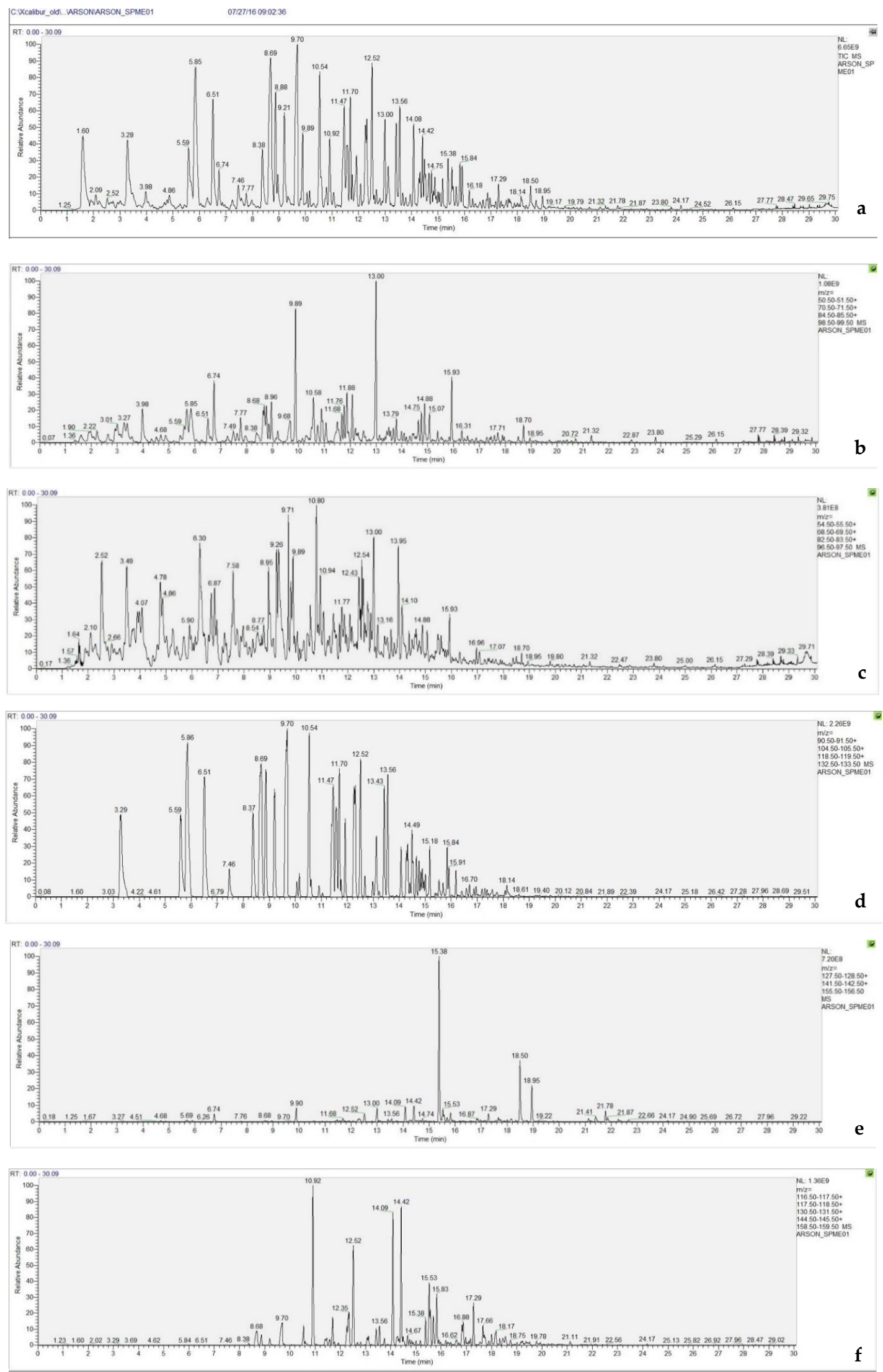

Figure 1. GC-MS extracted ion data related to neat gasoline. (a) Total ion chromatogram; (b) extracted alkane profile; (c) extracted cycloalkanes and alkenes profile; (d) aromatics (alkylbenzenes) profile; (e) extracted polynuclear aromatics profile; (f) extracted indane profile. 
The TIC pattern and the extracted profiles for kerosene using HS-SPME were not found in the literature but the obtained pattern (Figure 2a) presents the disproportionality abundant homologous series of n-alkanes and the less abundant cycloalkanes, which are the characteristics for kerosene. The extracted profiles were also comparable with those obtained using the ACS method provided in the literature [5]. The following target compounds of kerosene were identified: nonane (RT $=6.80 \mathrm{~min}$, $\mathrm{RSI}=881)$, decane $(\mathrm{RT}=10.09 \mathrm{~min}, \mathrm{RSI}=931)$, undecane $(\mathrm{RT}=13.19 \mathrm{~min}, \mathrm{RSI}=922)$, and dodecane $(\mathrm{RT}=16.00 \mathrm{~min}, \mathrm{RSI}=926)$.
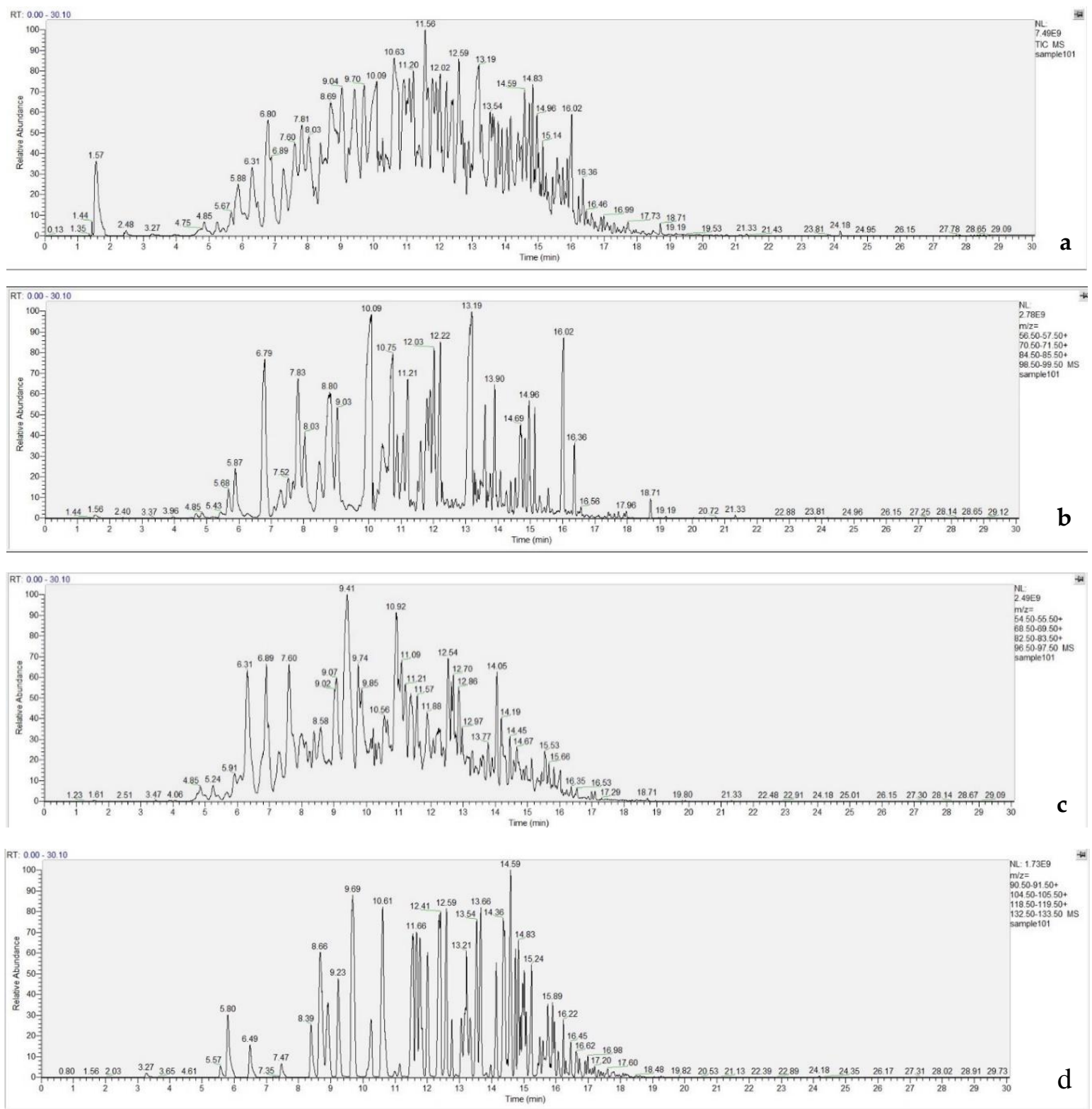

Figure 2. Cont. 


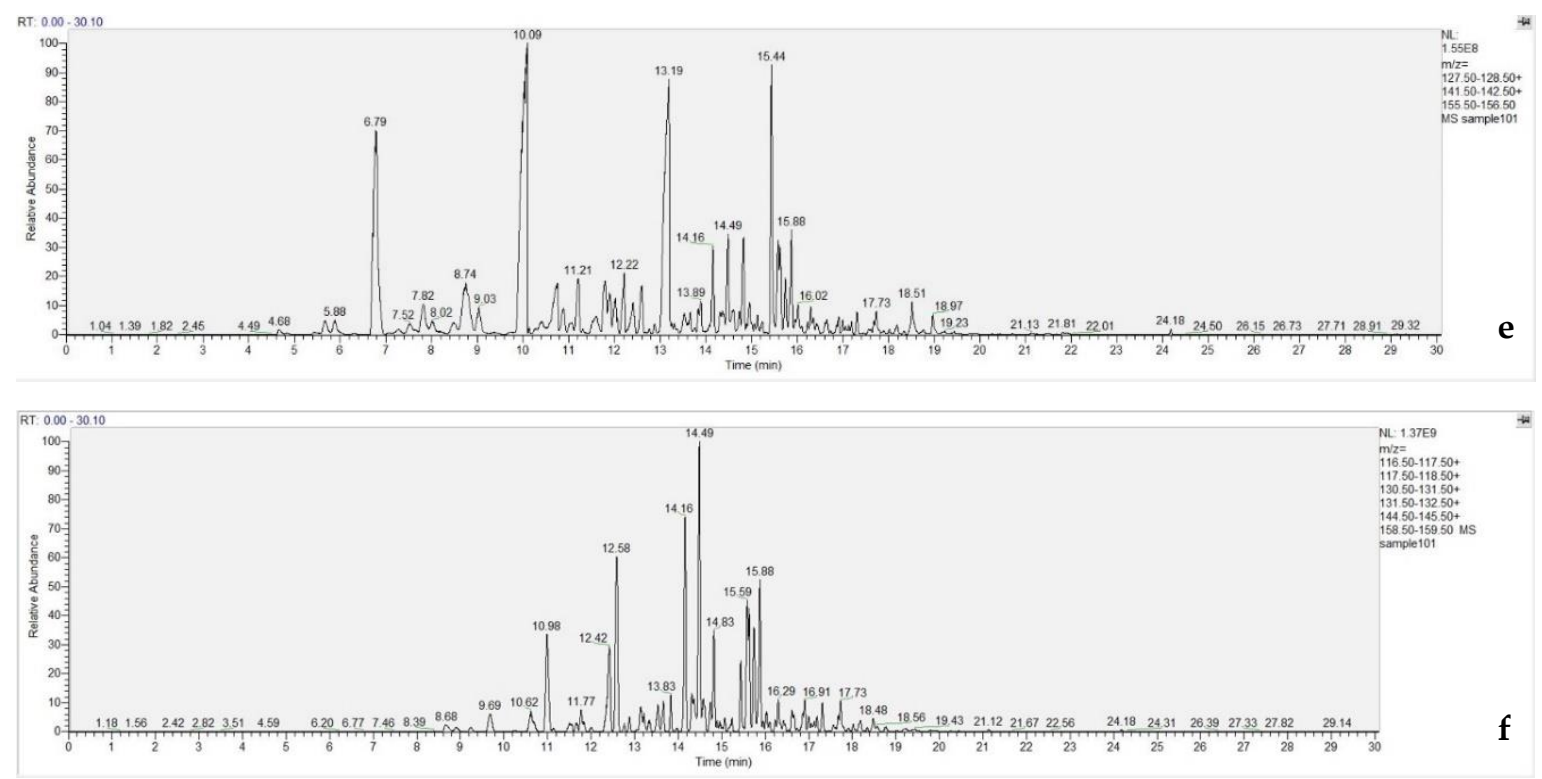

Figure 2. GC-MS extracted ion data related to neat kerosene. (a) Total ion chromatogram; (b) extracted alkane profile; (c) extracted cycloalkanes and alkenes profile; (d) aromatics (alkylbenzenes) profile; (e) extracted polynuclear aromatics profile; (f) extracted indane profile.

\subsection{Extracted Ion Data for Carpet Substrates}

To be able to study the possible interferences of commonly used carpet substrates in the analysis of ILs, three different types of carpet were chosen. Carpet \#1was a Stain Master Pet Protect Carpet with the color concord-mystical charm and the type of the carpet was plush, 100\% Stain Master Dyed BCF Nylon. Carpet \#2 was Stain Master Essential Carpet with the color fancy flair-antique lace and the type of carpet was plush. Carpet \#3 was Berber 100\% Dyed Polyester with the color 46016 Seneca. The total ion chromatograms and the extracted ion profiles for carpet samples burned with and without ILs are provided in the Supplementary Materials. In the following sections, selected chromatograms are provided for comparison purposes.

\subsubsection{Carpet \#1 Stain Master Pet Protect (Nylon 6,6)}

\section{Potential Interference with Identification of Gasoline}

Comparison of the total ion chromatograms obtained for carpet \#1 sample burned without ILs with that of unburnt neat gasoline, suggests the presence of interfering compounds and it can be suspected that gasoline is present in the sample (Figure 3). The following interfering compounds were identified in carpet burned without ILs: toluene (RT $=3.30 \mathrm{~min}$, RSI $=900)$, ethylbenzene $(\mathrm{RT}=5.61 \mathrm{~min}, \mathrm{RSI}=948), \mathrm{m}$ - $\mathrm{p}$ - xylene $(\mathrm{RT}=5.86 \mathrm{~min}, \mathrm{RSI}=892), \mathrm{n}$-propylbenzene $(\mathrm{RT}=8.37 \mathrm{~min}$, RSI $=908)$, and naphthalene $(R T=15.38 \mathrm{~min}, \mathrm{RSI}=912)$. However, the extracted ion profiles of carpet burned without ILs and unburned neat gasoline present distinguishable differences. In other words, although the extracted ion profiles of the two samples have common peaks (e.g., extracted alkylbenzene profile), the peak abundance ratios are not similar, indicating that gasoline is not present in the sample. However, since the carpet was burned and the neat gasoline was unburned, it might be argued that the difference is due to the evaporation, degradation, or combustion of the potentially present gasoline in the sample. To clear this ambiguity, the TIC and the extracted ion profiles of the carpet \#1 burned with gasoline were obtained and compared to those of neat gasoline and carpet \#1 burned without ILs. 

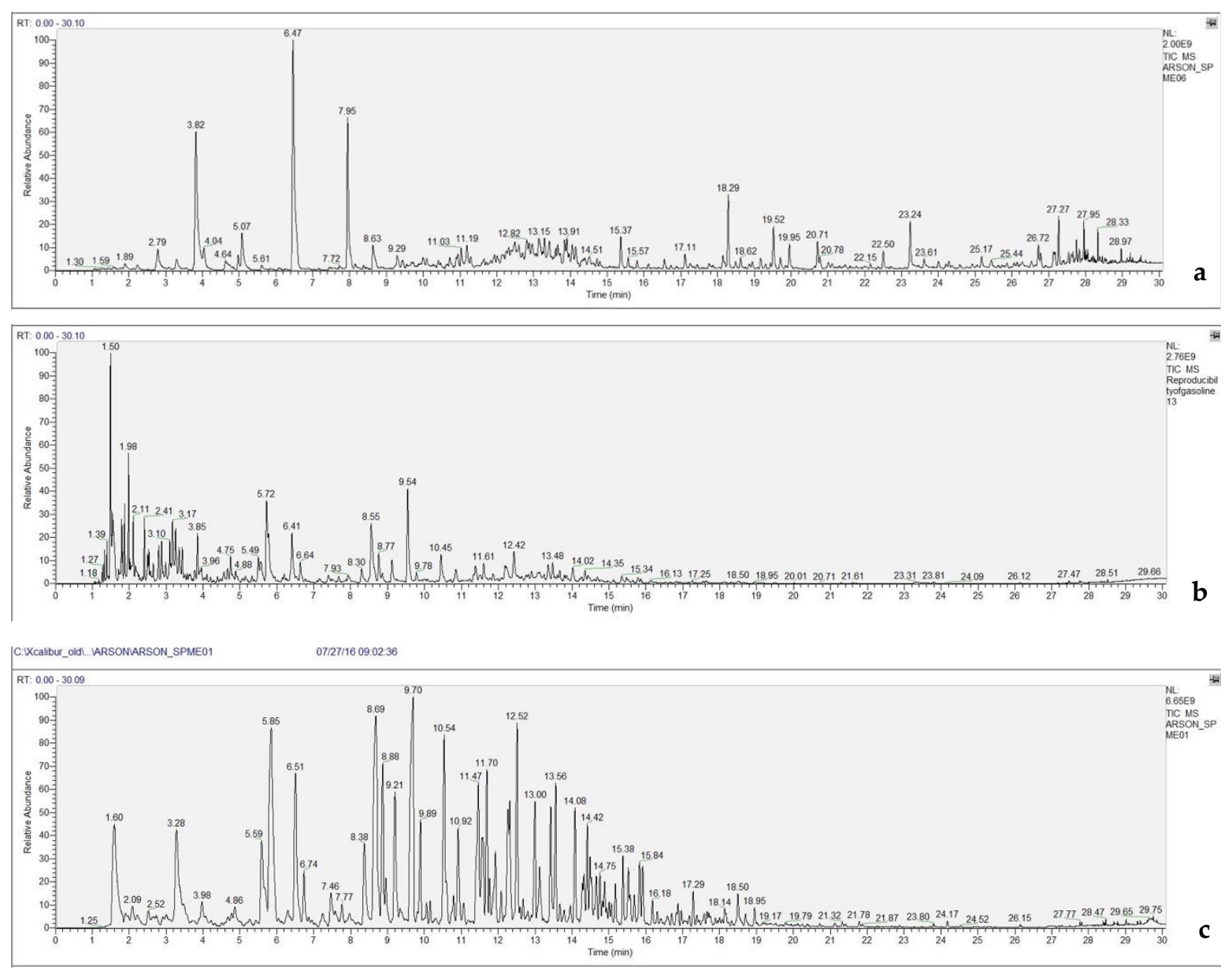

Figure 3. Total ion chromatograms $(m / z 50-500)$ of (a) carpet \#1, burned without ILs; (b) carpet \#1 burned with gasoline; and (c) neat gasoline.

A comparison of the TIC and extracted ion profiles of carpet \#1 burned with gasoline and neat gasoline (Figure 3b,c) shows clear similarities. All target compounds of gasoline were identified in the carpet burned with gasoline and with the same proportions as found in neat gasoline.

The comparison of the extracted ion profile for alkylbenzene compounds in neat gasoline with that of carpet \#1 burned without ILs clearly shows that even though some of the characteristic alkylbenzene compounds of gasoline are present in carpet \#1 burned without gasoline (Figure 4a), the abundance and peak ratios are different from that of neat gasoline (Figure 4c). The abundance and peak ratios of alkylbenzene compounds in the carpet burned with gasoline (Figure $4 \mathrm{~b}$ ), however, are comparable with those of neat gasoline (Figure 4c), making it easy to distinguish between the presence and absence of gasoline in the fire debris.

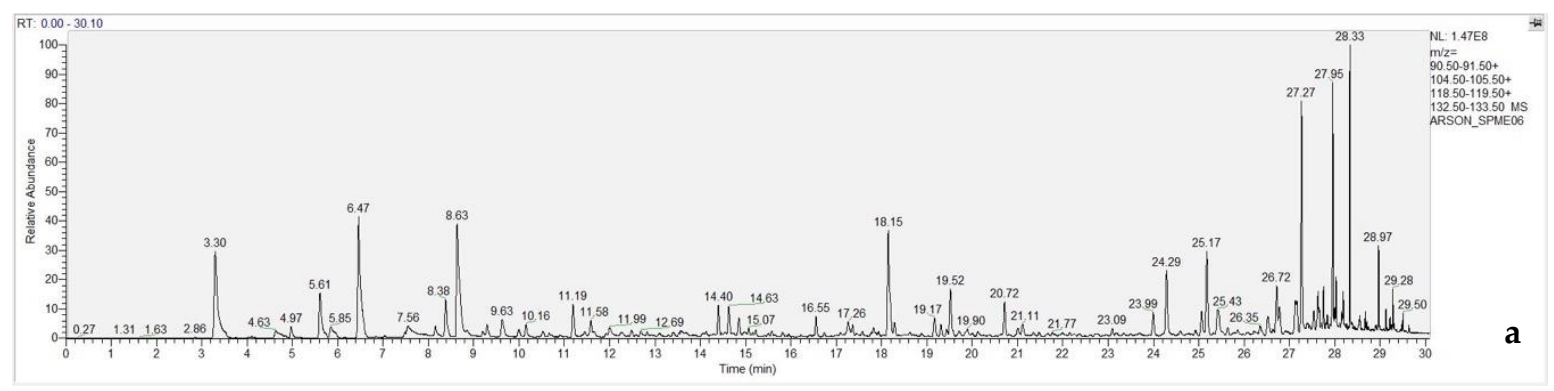

Figure 4. Cont. 

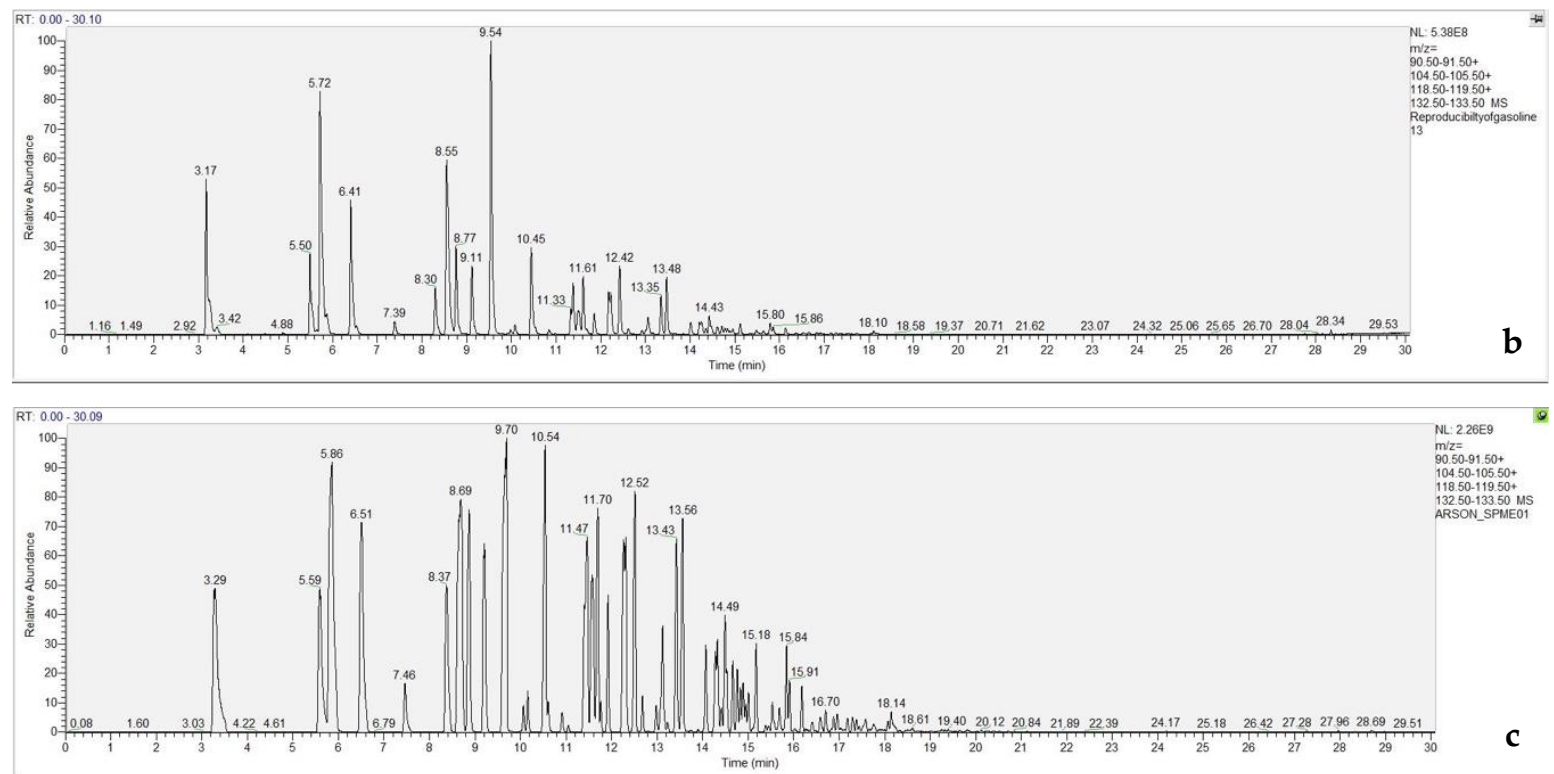

Figure 4. Extracted aromatic (alkylbenzenes) profiles of (a) carpet \#1 burned without ILs; (b) carpet\#1 burned with gasoline; and (c) neat gasoline.

To further investigate the presence of interfering compounds in carpet \#1, the extracted polynuclear aromatics profiles were compared (Figure 5$)$, and naphthalene ( $R T=15.38 \mathrm{~min}, \mathrm{RSI}=943)$ was identified in carpet \#1 burned without ILs, which is also present in carpet burned with gasoline (RT = $15.37 \mathrm{~min}$, RSI = 925), and neat gasoline (RT = $15.38 \mathrm{~min}, \mathrm{RSI}=925)$. Therefore, based on the extracted polynuclear aromatics profiles, the carpet burned without ILs cannot be distinguished from the carpet burned with gasoline, and naphthalene is an interfering compound in the analysis of gasoline.
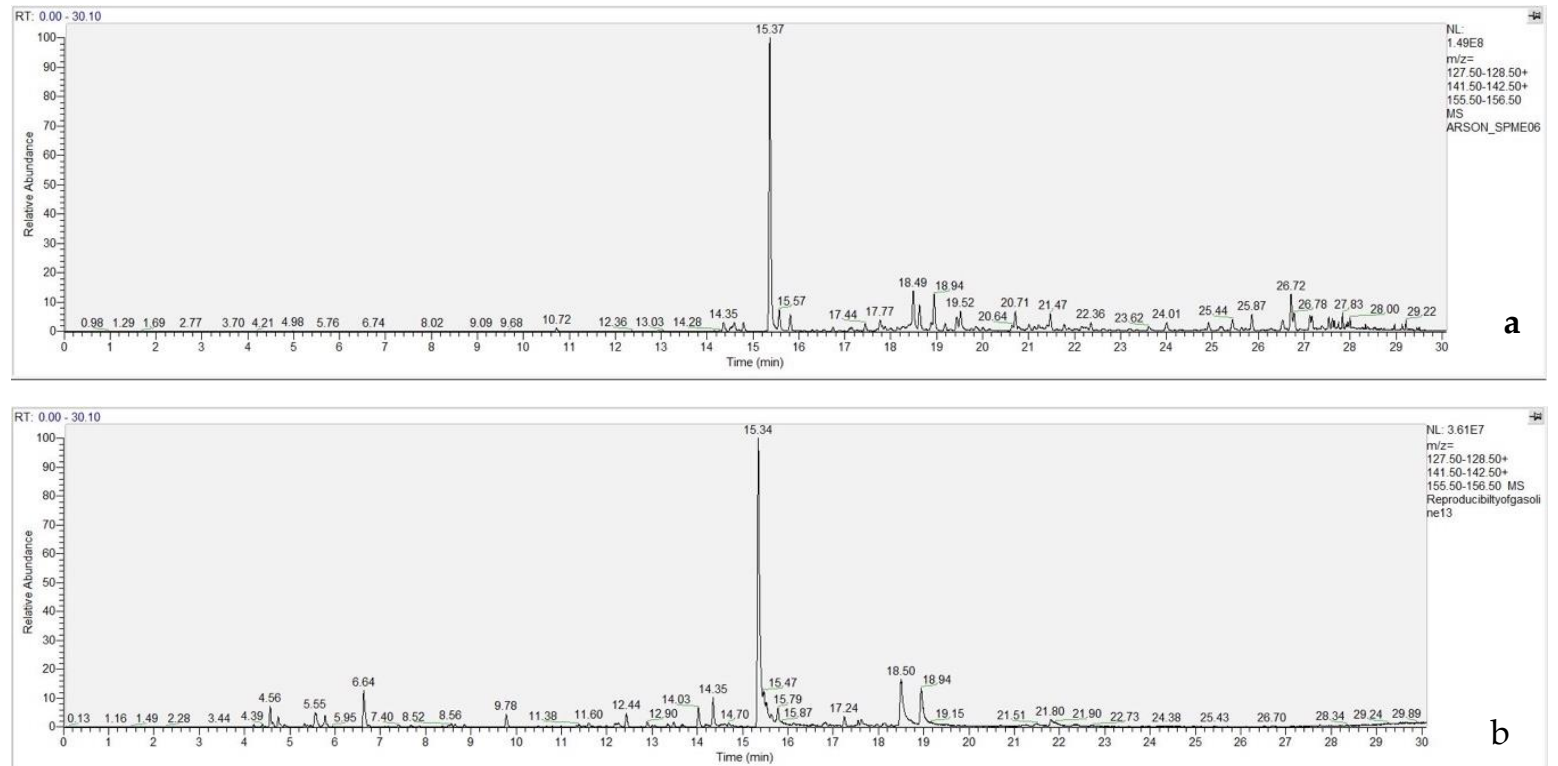

Figure 5. Cont. 


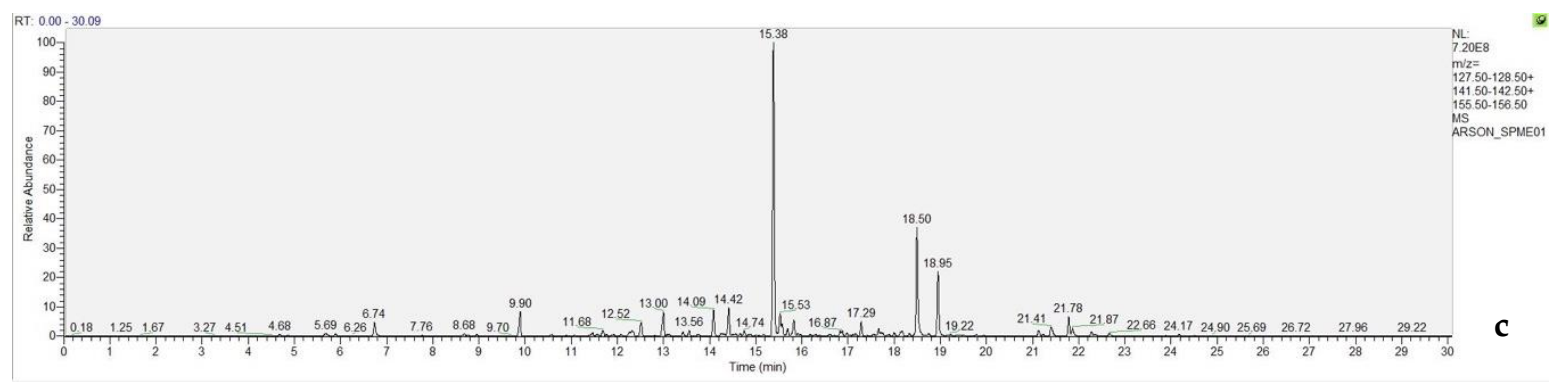

Figure 5. Extracted polynuclear aromatics profiles of (a) carpet \#1, burned without ILs; (b) carpet \#1 burned with gasoline; and (c) neat gasoline.

A comparison of the indane profiles shows that the pattern and intensities of peaks in chromatograms obtained from carpet \#1 without ILs (Figure 6a) are different from that of neat gasoline (Figure 6c). Identification of peaks showed indane was present in neat gasoline ( $R T=10.92 \mathrm{~min}$, RSI = 919) and carpet \#1 burned with gasoline (RT = $10.84 \mathrm{~min}, \mathrm{RSI}=904$; however, this compound was not identified in the chromatogram of carpet burned without ILs (Figure 6a). The characteristic indane profile of gasoline was clearly observed for carpet \#1 burned with gasoline (Figure 6b), indicating that the indane profile can be reliably used to identify gasoline in the fire debris of carpet \#1.
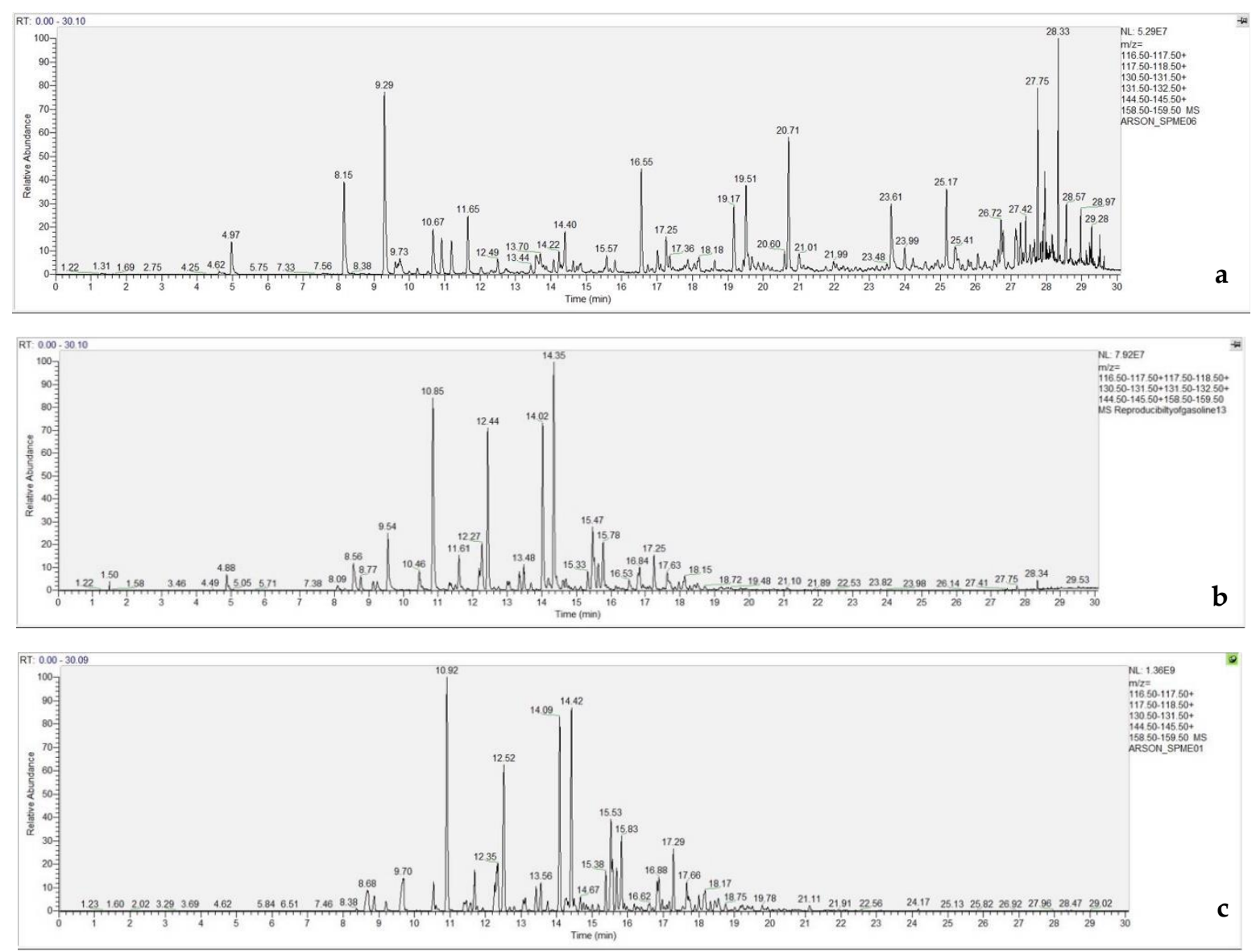

Figure 6. Extracted indane profiles of (a) carpet \#1 burned without ILs; (b) carpet \#1 burned with gasoline; and (c) neat gasoline.

It is concluded that the tested SPME method, together with the extracted ion profile pattern recognition, can successfully and reliably determine the presence or absence of gasoline in fire debris with Stain Master Pet Protect (nylon 6,6) substrate material. 
Potential Interference with the Identification of Kerosene

A comparison of the TIC of carpet \#1 burned without ILs (Figure 7a) with that of neat kerosene (Figure 7c) shows that there might be interference with the identification of kerosene, especially in the area between 11.00 to $15.00 \mathrm{~min}$. The library search suggested the presence of alkenes or cycloalkanes, which could indicate the presence of an IL. However, the extracted cycloalkane profiles do not show the same patterns as neat kerosene. The TIC of carpet burned with kerosene (Figure 7b) is less complex compared to neat kerosene (Figure 7c), probably due to the evaporation of n-alkanes and cycloalkanes; however, the extracted ion profiles have common peak patterns with that of neat kerosene, and kerosene target compounds were identified as Nonane $(\mathrm{RT}=6.73 \mathrm{~min}, \mathrm{RSI}=917)$, decane $(\mathrm{RT}=9.88 \mathrm{~min}$, RSI = 937), undecane $(\mathrm{RT}=12.95 \mathrm{~min}, \mathrm{RSI}=900)$, and dodecane $(\mathrm{RT}=15.91 \mathrm{~min}, \mathrm{RSI}=928)$, which are not present in carpet burned without ILs.
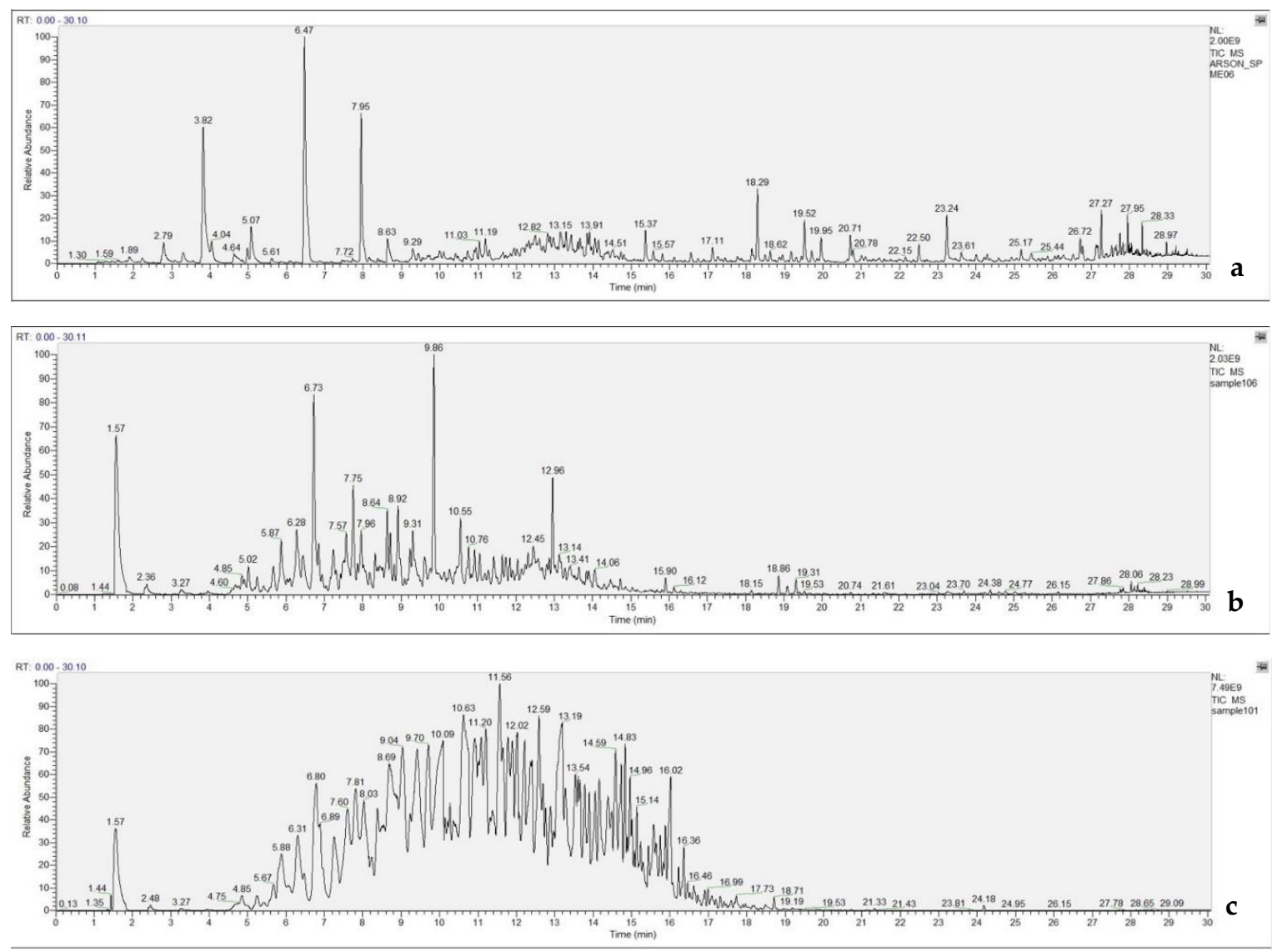

Figure 7. Total ion chromatograms ( $m / z 50-500)$ of (a) carpet \#1, burned without ILs; (b) carpet \#1 burned with kerosene; and (c) neat kerosene.

A comparison of the TICs of the SPME extracts of carpet \#1 burned without ILs and in the presence of gasoline and kerosene, indicates that the chromatograms are easily distinguishable. The main pyrolysis product of nylon 6,6 polymer was identified as styrene $(\mathrm{RT}=6.47$, $\mathrm{RSI}=956)$, which has been reported to be a pyrolysis product of nylon at temperatures between $400{ }^{\circ} \mathrm{C}$ and $700{ }^{\circ} \mathrm{C}$ in the literature [15]. Nylon fibers are known to be resistant to fire and it was not easy to burn the fiber in the absence of ILs and the fiber burned without a flame. In the presence of ILs, the fiber burned to produce a flaming fire, which explains the reduction in the relative abundance of styrene in the chromatograms obtained in the presence of ILs. The generated heat of the flame can result in degradation and evaporation of styrene. 


\subsubsection{Carpet \#2 Stain Master Essential Carpet}

To investigate the effect of the background interferences of carpet substrates made from polyester in arson analysis, the Stain Master Essential Carpet (carpet \#2) was burned in the absence and presence of ILs (Figure 8). The pyrolysis products identified in the chromatogram of carpet \#2 burned without $I L s$, were benzene $(R T=1.81 \mathrm{~min}, \mathrm{RSI}=951)$, toluene $(\mathrm{RT}=3.17 \mathrm{~min}, \mathrm{RSI}=957)$, styrene $(\mathrm{RT}=6.30 \mathrm{~min}$, $\mathrm{RSI}=944)$, benzaldehyde $(\mathrm{RT}=8.46 \mathrm{~min}, \mathrm{RSI}=945)$, and naphthalene $(\mathrm{RT}=15.19 \mathrm{~min}, \mathrm{RSI}=925)$, which were consistent with those reported in the literature using the activated charcoal strip (ACS) method for polyester fibers [11].
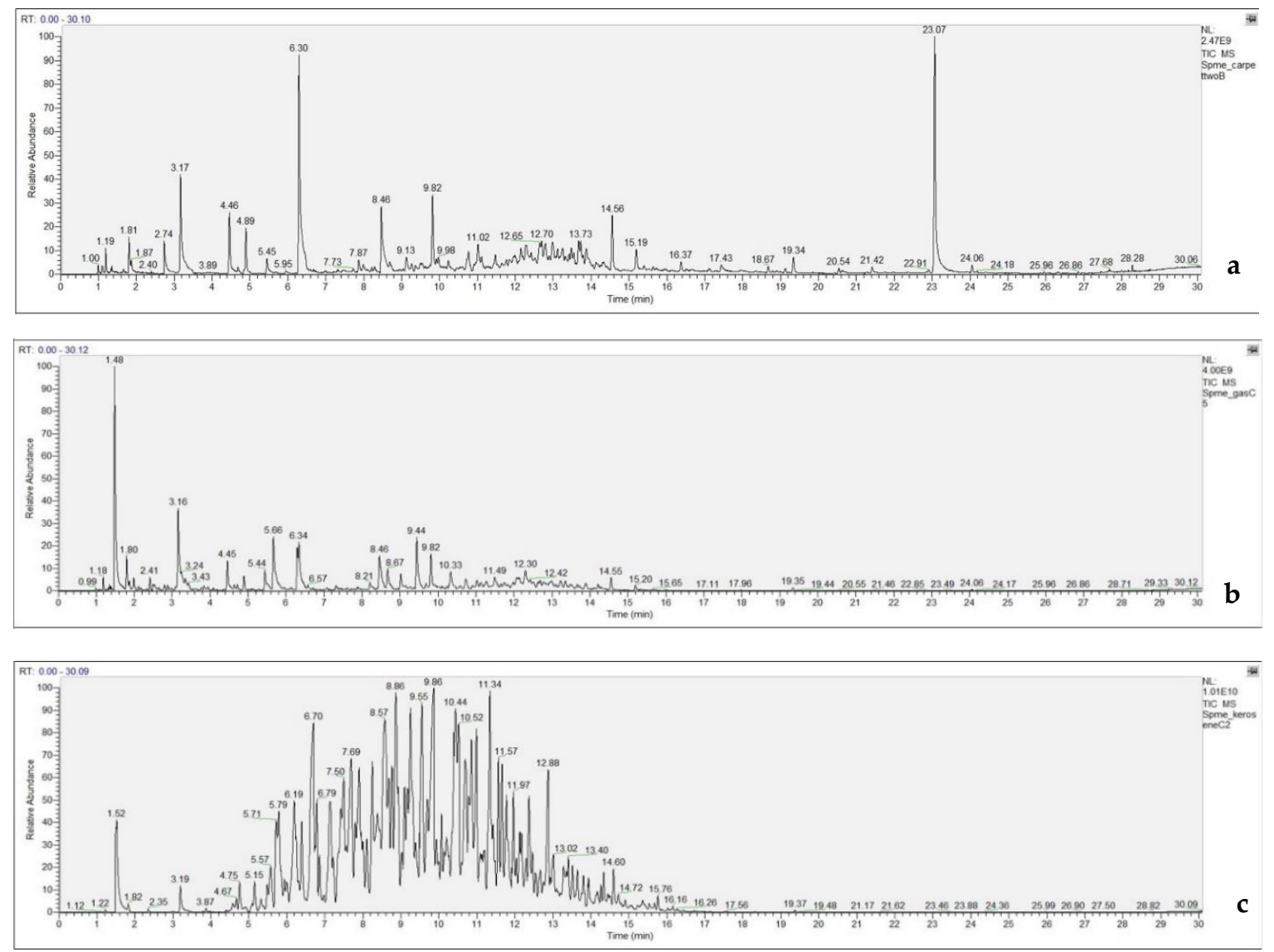

Figure 8. Total ion chromatograms ( $m / z$ 50-500) of carpet \#2 (a) burned without ILs; (b) burned with gasoline; and (c) burned with kerosene.

Potential Interference with the Identification of Gasoline

The examination of the TIC of carpet \#2 burned without ILs shows potential interferences with the identification of gasoline. However, comparing the alkylbenzene profiles of carpet \#2 burned without ILs and neat gasoline shows that the abundance and the peak ratios are not consistent with the pattern observed for gasoline. The comparison of polynuclear aromatic profiles of carpet \#2 burned without ILs with that of neat gasoline also shows an interference at retention time of $15.19 \mathrm{~min}$, which was identified as naphthalene (RSI $=925)$. Although some indane derivatives were identified in carpet \#2 burned without ILs (Figure 9a), the retention times and the peak abundance relative ratios were not consistent with the indane compounds identified in neat gasoline (Figure 9c) and carpet \#2 burned with gasoline (Figure $9 \mathrm{~b}$ ). The indane profile for carpet \#2 burned with gasoline shows the characteristic indane profile observed in neat gasoline, which makes the indane profile a suitable profile for the identification of gasoline in the charred debris of carpet $\# 2$. 


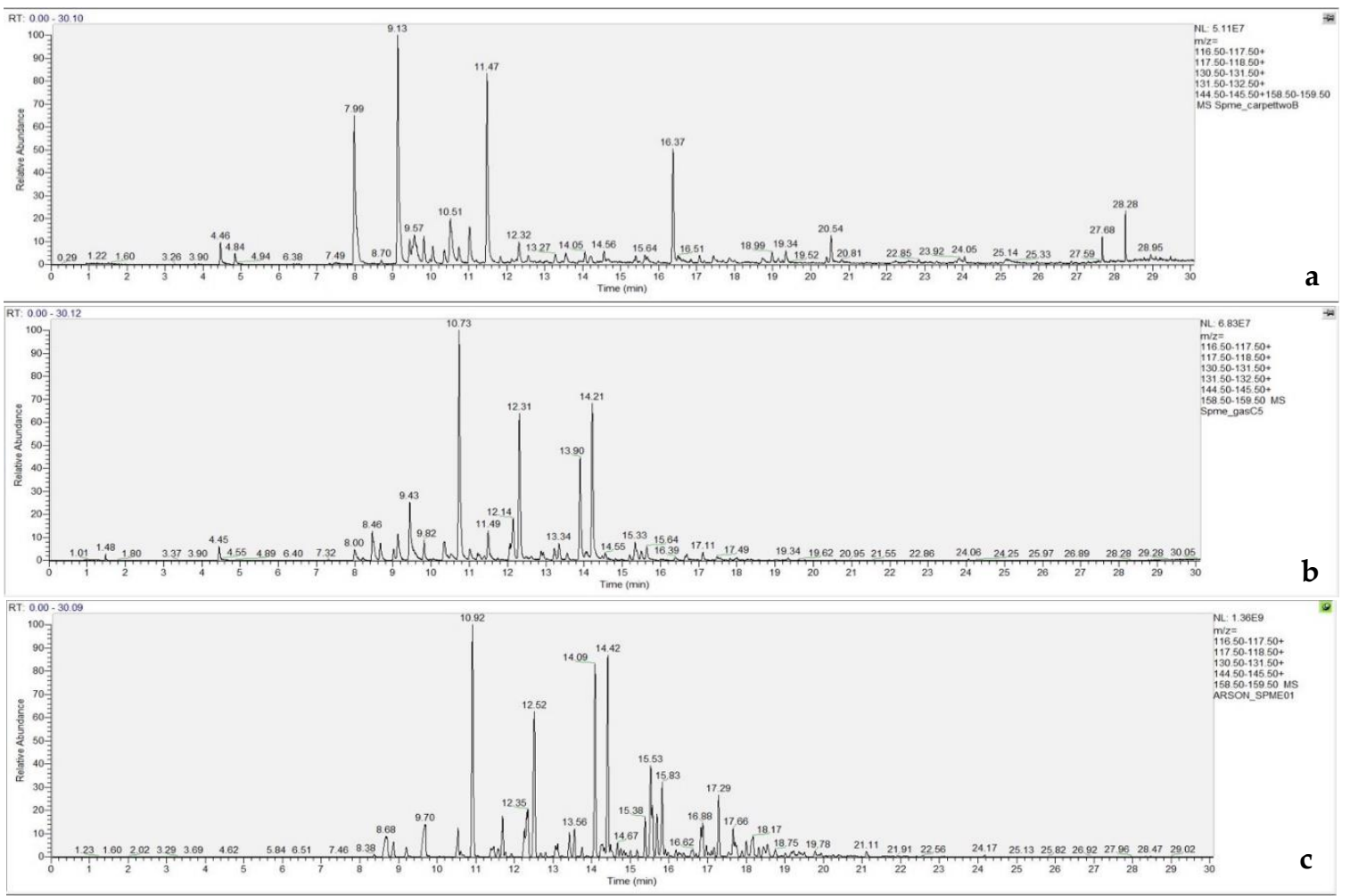

Figure 9. Extracted indane profiles of (a) carpet \#2, burned without ILs; (b) carpet \#2 burned with gasoline; and (c) neat gasoline.

Potential Interference with the Identification of Kerosene

The TIC and extracted ion profiles for carpet \#2 burned without IL do not show interferences with kerosene. The TIC and the extracted ion profiles obtained for carpet \#2 burned with kerosene match very well with those obtained with neat kerosene. The obtained profiles are distinguishable from carpet burned without ILs, indicating that this method can be reliably used for the identification of kerosene in the charred debris of carpet \#2.

Comparison of the TICs of the SPME extracts of carpet \#2 burned without ILs and in the presence of gasoline and kerosene (Figure 8), indicates that the chromatograms are easily distinguishable and that this method can successfully be used to identify gasoline and kerosene in charred Stain Master Essential (polyester) carpet.

\subsubsection{Extracted Ion Data for Carpet \#3 Berber 100\% Dyed Polyester Carpet}

The third studied carpet was Berber 100\% Dyed Polyester carpet. The TIC and extracted ion profiles for this carpet burned in the absence and presence of ILs is presented in Figure 10. The identified compounds in carpet \#3 were benzene $(\mathrm{RT}=1.81 \mathrm{~min}, \mathrm{RSI}=938)$, phenol $(\mathrm{RT}=2.98 \mathrm{~min}, \mathrm{RSI}=969)$, toluene $(\mathrm{RT}=3.17 \mathrm{~min}, \mathrm{RSI}=956), 2,4$-dimethy-1-heptene $(\mathrm{RT}=4.89 \mathrm{~min}, \mathrm{RSI}=947)$, ethylbenzene $(\mathrm{RT}=5.45 \mathrm{~min}, \mathrm{RSI}=932)$, and styrene $(\mathrm{RT}=6.30 \mathrm{~min}, \mathrm{RSI}=948)$. 

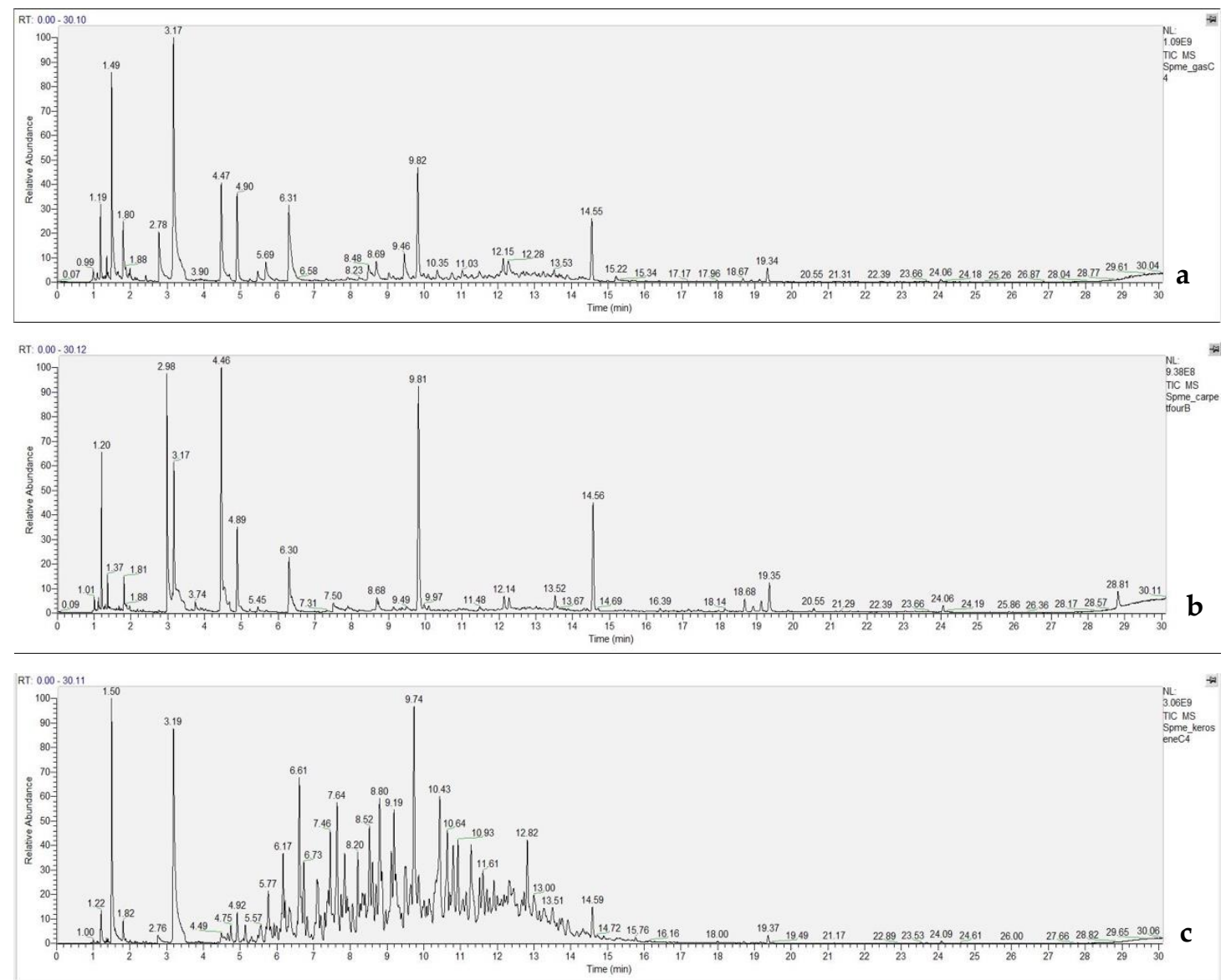

Figure 10. Total ion chromatograms ( $m / z$ 50-500) of carpet \#3 (a) burned without ILs; (b) burned with gasoline; (c) burned with kerosene.

Potential Interference with the Identification of Gasoline

Although toluene and ethyl benzene, target compounds of gasoline, were identified in carpet \#3 burned without ILs, a comparison of extracted ion profiles in carpet \#3 burned without ILs with that of neat gasoline shows that the profiles are distinguishable based on the number of identified compounds and the relative abundance. The profiles obtained from carpet \#3 burned with gasoline clearly demonstrate the characteristic alkylbenzene, polyaromatics, and indane profiles of gasoline. The extracted alkylbenzene profiles are compared in Figure 11 as an example. It should be noted that the relative peak abundance for toluene $(\mathrm{RT}=3.17 \mathrm{~min}, \mathrm{RSI}=956)$ is much higher compared to the other characteristic alkylbenzenes since, it is also a pyrolysis product of polyester carpet.

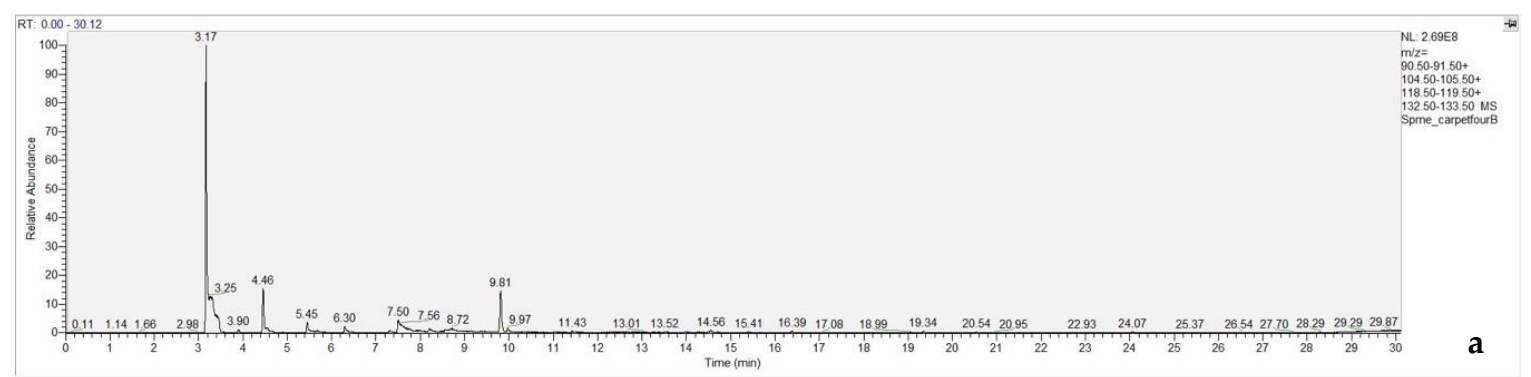

Figure 11. Cont. 

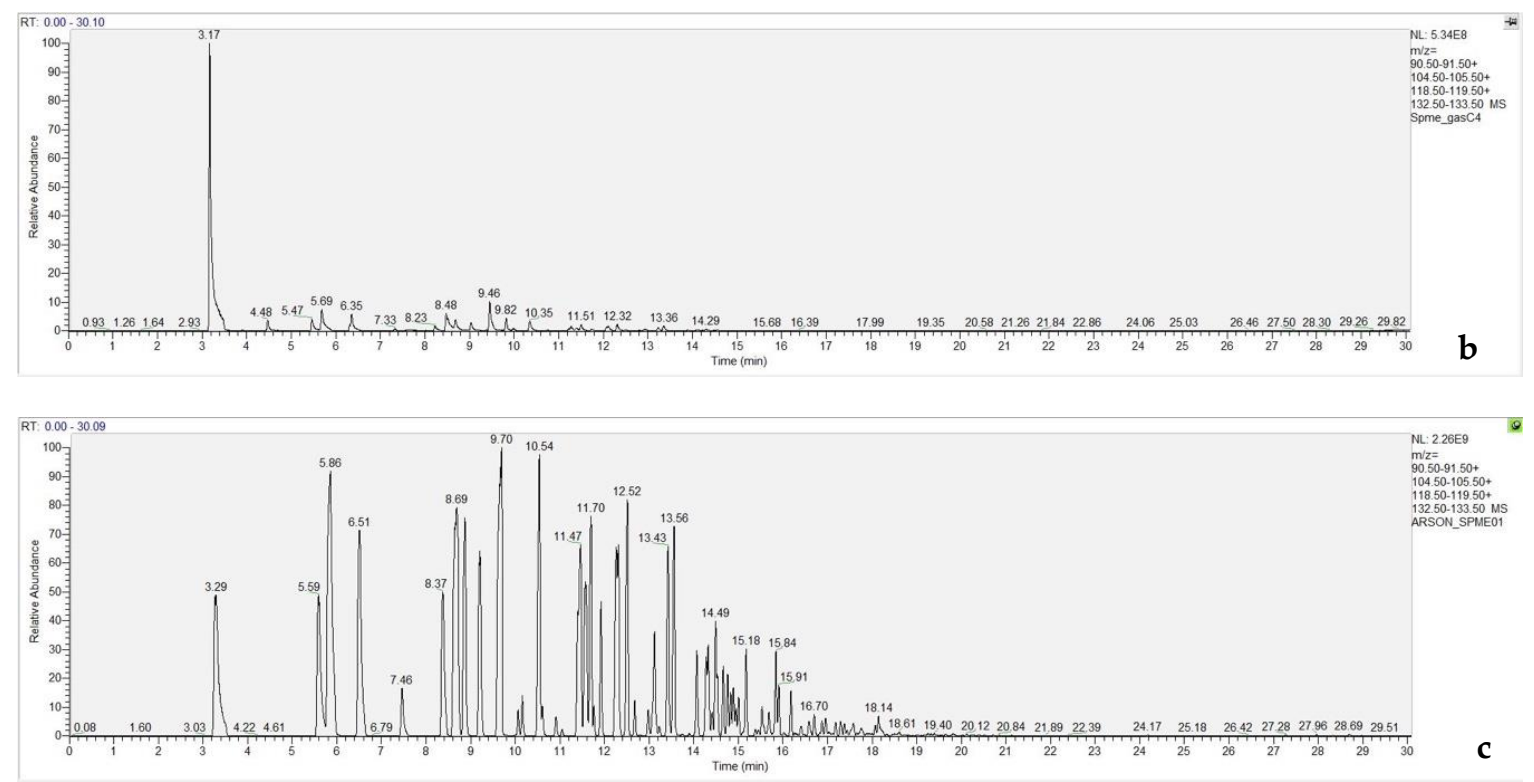

Figure 11. Extracted aromatic (alkylbenzenes) profiles of (a) carpet \#3 burned without ILs; (b) carpet\#1 burned with gasoline; and (c) neat gasoline.

Comparison of the extracted indane profiles of carpet \#3 burned with and without gasoline with the indane profile of neat gasoline, shows that the indane profile can be reliably used to confirm the presence of gasoline. The indane profile of carpet \#3 burned without gasoline does not match with that of neat gasoline, whereas the indane profile of carpet \#3 burned with gasoline matches with that of neat gasoline (Figure 12).

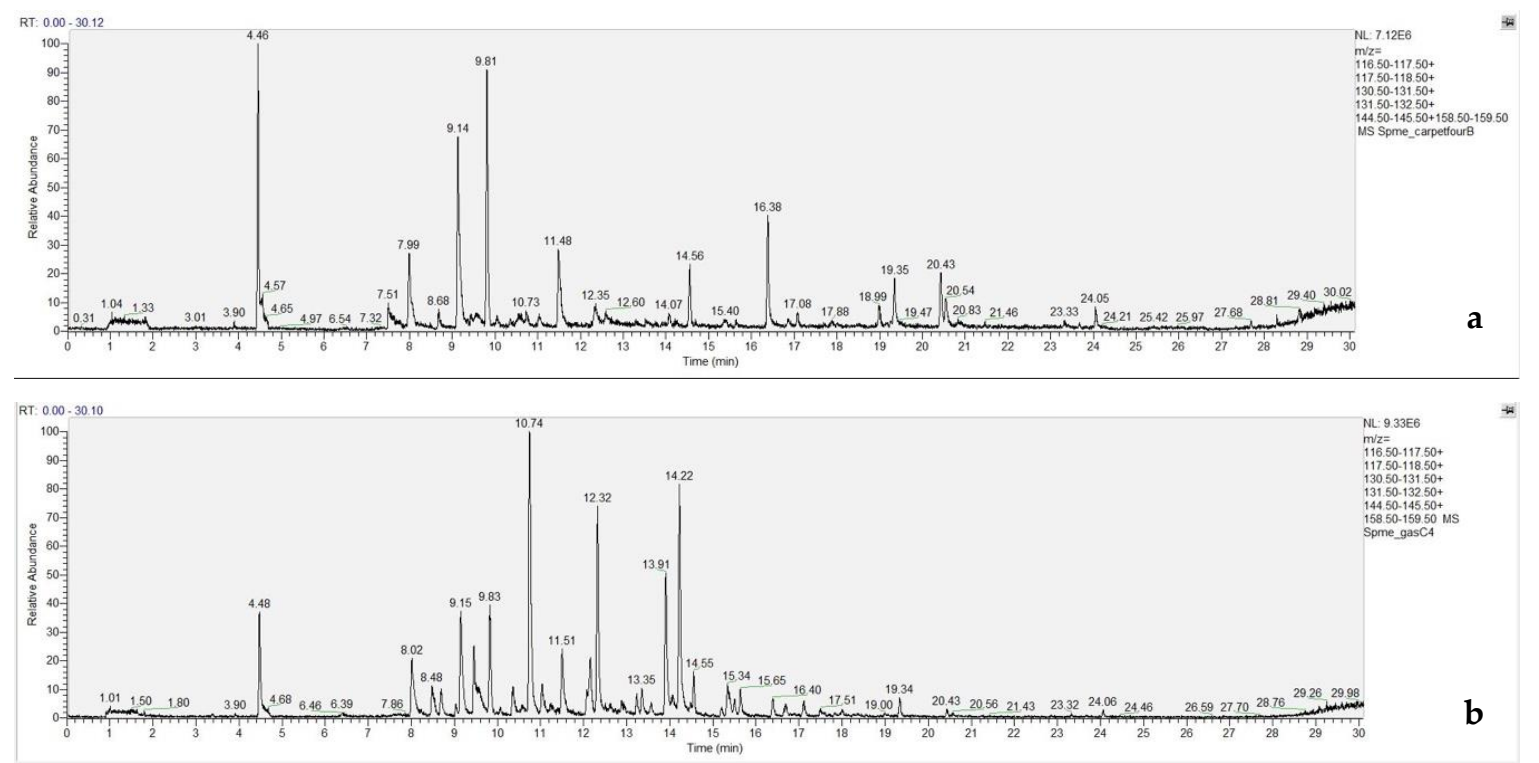

Figure 12. Cont. 


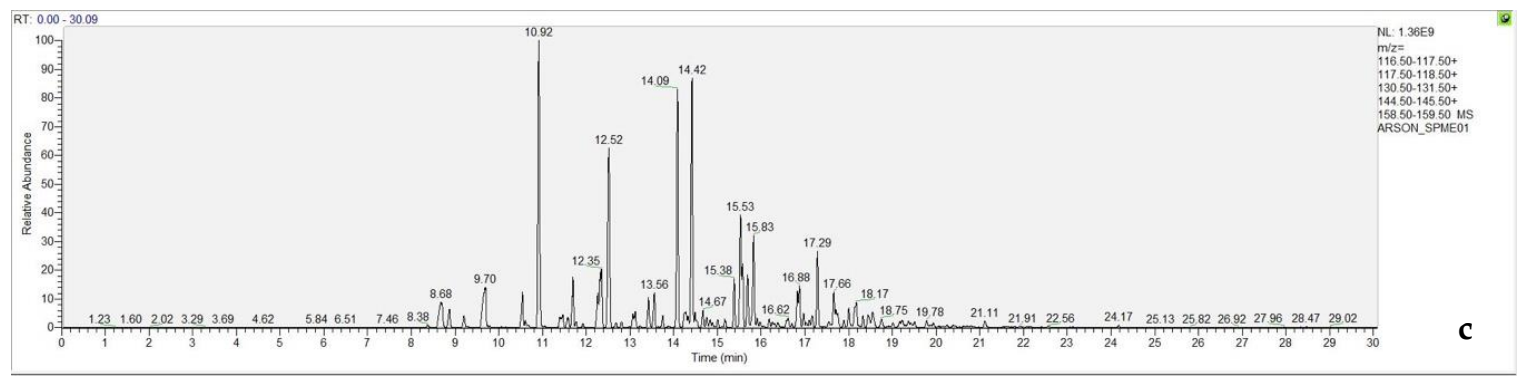

Figure 12. Extracted indane profiles of (a) carpet \#3 burned without ILs; (b) carpet \#3 burned with gasoline; and (c) neat gasoline.

Potential Interference with Identification of Kerosene

Comparison of the profiles obtained for carpet \#3 burned without kerosene and those of unburned neat kerosene does not show interferences. On the other hand, the TIC and extracted ion profiles obtained from carpet \#3 burned with kerosene, present the characteristic alkane, and cycloalkane profiles of kerosene. The obtained results clearly demonstrate that the tested SPME method can be reliably used to distinguish between carpet burned without ILs and carpet burned with kerosene.

The extracted alkane profiles of carpet burned without ILs is compared to those of carpet burned with kerosene and neat kerosene, for example in Figure 13.
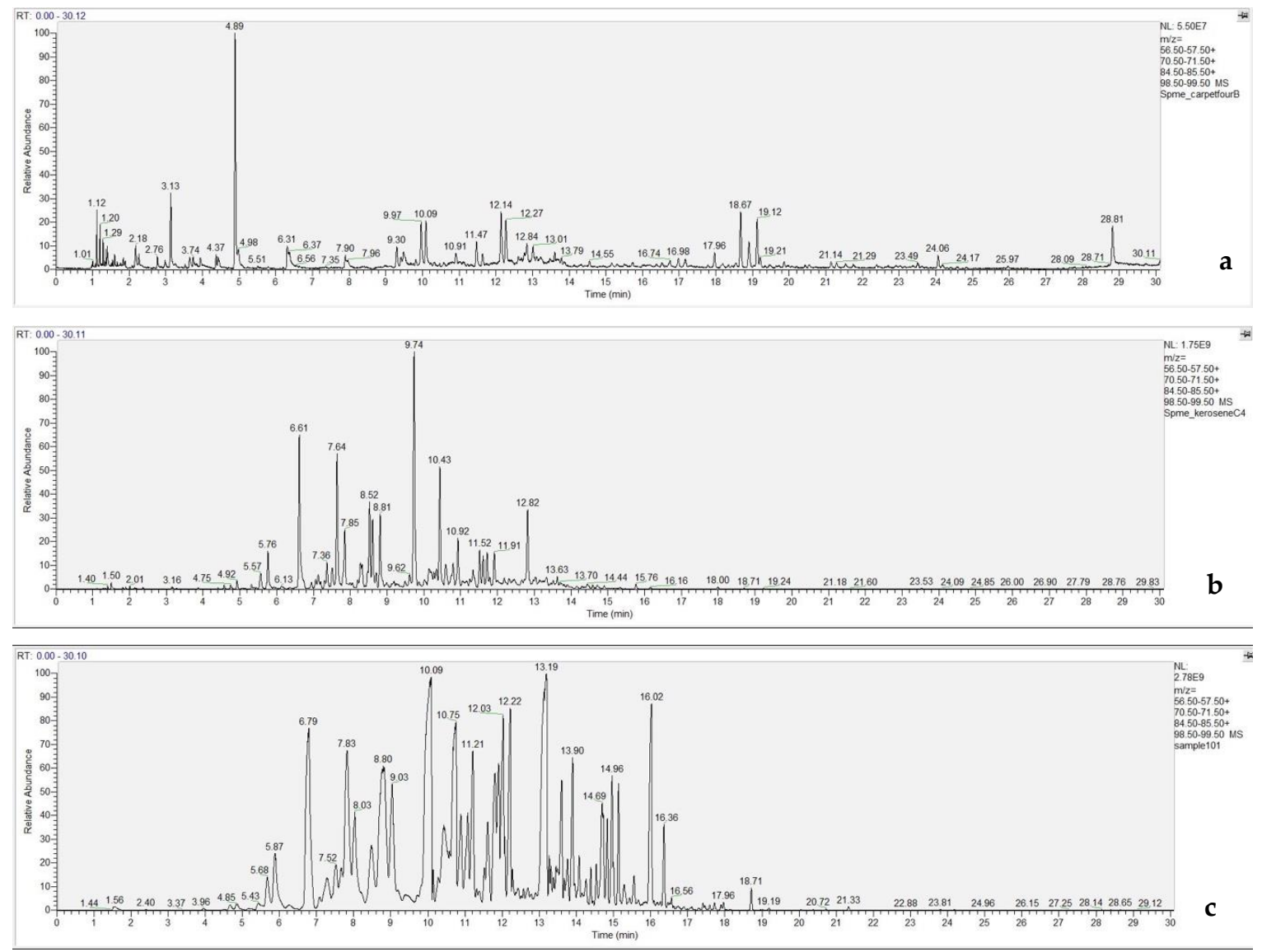

Figure 13. Extracted alkane profiles of (a) carpet \#3 burned without ILs; (b) carpet \#3 burned with kerosene; and (c) neat kerosene. 


\section{Discussion}

An HS-SPME method was tested and applied in the study of the background interferences of three commonly used carpets, namely, Stain Master Pet Protect Dyed BCF Nylon 6,6, and Stain Master Essential carpet, for the identification of gasoline and kerosene in fire debris. The main purpose of the study was to demonstrate that SPME can be reliably used for the identification of ILs, if combined with GC-MS. Mass spectrometry provides the option of extracted ion profiles, which helps interpret the data when substrate background interferences make it difficult to make a solid decision based solely on the TICs. To show the reliability of the method in the interpretation of arson data, each carpet was burned in different conditions, namely, without ILs, with gasoline, and with kerosene. The TIC and extracted ion profiles of unburned neat gasoline and kerosene were also obtained for comparison purposes. The results showed that in general all carpets showed a few target compounds of gasoline (alkylbenzenes and polynuclear aromatics) when burned without ILs; however, the extracted profiles showed that the peak abundance ratios of alkylbenzenes and indanes were different from the characteristic ratios expected for gasoline, whereas the carpet samples burned with gasoline clearly showed the alkylbenzene and indane profiles with the same peak abundance ratios as neat gasoline. Naphthalene was identified as an interference in all three carpet substrates making the polynuclear aromatics profiles not suitable for analysis. Unlike gasoline, target alkane compounds of kerosene were not identified in carpets burned without ILs. The TICs and extracted ion profiles of carpets burned with kerosene clearly showed the characteristic profiles expected for kerosene. It can be concluded that this method can reliably be used for the identification of gasoline and kerosene in charred fire debris with the carpets included in this study as substrate material. To our knowledge, such a study of carpet substrate showing extracted ion profiles for carpet burned with gasoline and kerosene using HS-SPME as the extraction method has not been reported in the literature. Considering the advantages of SPME over other extraction techniques, the present study is valuable in providing forensic labs with a reliable method. Moreover, the provided data can help forensic labs interpret their fire debris data more reliably and demonstrates that SPME, although merely accepted as a screening test, is as reliable as the ACS method, which is accepted as the confirmatory test for ILR analysis.

Supplementary Materials: The following are available online at http://www.mdpi.com/2297-8739/7/4/63/s1.

Author Contributions: Conceptualization, S.H.; methodology, S.H.; software, S.H.; validation, S.H.; formal analysis, S.H.; investigation, A.A., E.G.-L., G.O., S.H.; resources, S.H. and A.A.; data curation, S.H.; writing-original draft preparation, S.H.; writing-review and editing, S.H.; visualization, S.H. and K.W.; supervision, S.H.; project administration, S.H.; funding acquisition, S.H. All authors have read and agreed to the published version of the manuscript.

Funding: This research received no external funding.

Acknowledgments: The authors would like to thank SUNY Oswego's Department of Chemistry for providing the instruments and the Challenge Grant program for financial support. Special thanks to Vadoud Niri and Nicholas Carusone for their help and support.

Conflicts of Interest: The authors declare no conflict of interest.

\section{References}

1. Almirall, J.R.; Furton, K.G. Analysis and Interpretation of Fire Scene Evidence; CRC Press LLC: Boca Raton, FL, USA, 2004; Available online: http://www.safetymessage.com/images/books/enpdf/fire/Analysis\%20and\% 20Interpretation\%20of\%20Fire\%20Scene\%20Evidence.pdf (accessed on 22 October 2020).

2. NFPA (National Fire Protection Association). Fires in the US. 2019. Available online: https://www.nfpa.org///media/Files/News-and-Research/Fire-statistics-and-reports/US-Fire-Problem/osFireLoss.pdf (accessed on 22 October 2020).

3. FBI (2019) Crime in the United States. Federal Bureau of Investigation. 2019. Available online: https:/ucr.fbi.gov/crime-in-the-u.s/2019/crime-in-the-u.s.-2019/topic-pages/arson (accessed on 22 October 2020).

4. Houck, M. Fire and Arson. In Advanced Forensic Science Series. Forensic Chemistry; Academic Press: Cambridge, MA, USA, 2015; p. 227. 
5. Siegel, J. Chapter 4, Forensic fire debris analysis. In Forensic Science in Focus, Forensic Chemistry Fundamentals and Application; Wiley-Blackwell: Hoboken, NJ, USA, 2016; pp. 136, 143-148.

6. Martín-Alber, C.; Ortega-Ojedab Carmen García-Ruizab, F.E. Analytical tools for the analysis of fire debris. Anal. Chim. Acta 2016, 928, 1-19. [CrossRef]

7. ASTM. ASTM E1412-12 Standard Practice for Separation of Ignitable Liquid Residues from Fire Debris Samples by Passive Headspace Concentration with Activated Charcoal; ASTM International: West Conshohocken, PA, USA, 2015; Available online: www.astm.org (accessed on 22 October 2020).

8. ASTM. ASTM E2154-15 Standar d Practice for Separation and Concentration of Ignitable Liquid Residues from Fire Debris Samples by Passive Headspace Concentration with Solid Phase Microextraction (SPME); ASTM International: West Conshohocken, PA, USA, 2015; Available online: www.astm.org (accessed on 22 October 2020).

9. ASTM. ASTM E1386-10 Standard Practice for Separation of Ignitable Liquid Residues from Fire Debris Samples by Solvent Extraction; ASTM International: West Conshohocken, PA, USA, 2010; Available online: www.astm.org (accessed on 22 October 2020).

10. ASTM. ASTM E1618-14 Standard Test Method for Ignitable Liquid Residues in Extracts from Fire Debris Samples by Gas Chromatography-Mass Spectrometry; ASTM International: West Conshohocken, PA, USA, 2014; Available online: www.astm.org (accessed on 22 October 2020).

11. International Database of Ignitable Liquids; National Center for Forensic Science, University of Central Florida: Orlando, FL, USA, 2006; Available online: http://ncfs.ucf.edu/databases/ (accessed on 22 October 2020).

12. Hendrikse, J.; Grutters, M.; Schäfer, F. Identifying Ignitable Liquids in Fire Debris: A Guideline for Forensic Experts; Elsevier Science \& Technology: Amsterdam, The Netherlands, 2016; Chapter 6; p. 31.

13. Fettig, I.; Krueger, S. Evaluation of a Headspace Solid-Phase Microextraction Method for the Analysis of Ignitable Liquids in Fire Debris. J. Forensic Sci. 2014, 59, 743-749. [CrossRef] [PubMed]

14. Li, Y.-Y.; Liang, D.; Shen, H. An analysis of background interference on fire debris. Procedia Eng. 2013, 52, 664-670. [CrossRef]

15. Leea, X.Q.; Mark, P.; Sandercockb, L.; Harynuka, J. The influence of temperature on the pyrolysis of household materials. J. Anal. Appl. Pyrolysis 2016, 118, 75-85. [CrossRef]

Publisher's Note: MDPI stays neutral with regard to jurisdictional claims in published maps and institutional affiliations.

(C) 2020 by the authors. Licensee MDPI, Basel, Switzerland. This article is an open access article distributed under the terms and conditions of the Creative Commons Attribution (CC BY) license (http://creativecommons.org/licenses/by/4.0/). 